\section{NAA and 3,5,6-TPA Control Mature Fruit Drop in California Citrus}

\author{
Michael F. Anthony ${ }^{1}$ and Charles W. Coggins, Jr. ${ }^{2}$ \\ Department of Botany and Plant Sciences, University of California, Riverside, \\ CA 92521
}

Additional index words. navel orange, Citrus sinensis, grapefruit, Citrus paradisi, triclopyr, 2,4-D, auxin, abscission

\begin{abstract}
The synthetic auxins NAA and 3,5,6-TPA were investigated for reducing abscission of mature citrus fruit in California (CA). NAA was investigated on navel orange trees in San Joaquin Valley and southern CA locations. Of the seven NAA experiments presented, five had substantial fruit drop. In these five experiments, a treatment of NAA reduced drop by $31 \%$ to $88 \%$ compared to the untreated control. Although NAA treatments as low as $25 \mathrm{mg} \cdot \mathrm{L}^{-1}$ (acid equivalent) reduced drop, the greatest reductions in drop were obtained by spray concentrations in the 100 to 400 $\mathrm{mg} \cdot \mathrm{L}^{-1}$ range. 3,5,6-TPA was investigated for fruit drop control properties on navel orange and grapefruit grown in various $\mathrm{CA}$ locations. The untreated control in seven of the ten 3,5,6-TPA experiments had substantial fruit drop. In each of these cases, a treatment of $10,15 \mathrm{or} 20 \mathrm{mg} \cdot \mathrm{L}^{-1}$ (acid equivalent) of 3,5,6-TPA reduced drop $69 \%$ to $96 \%$ compared to the untreated control. A strong linear response from 3,5,6-TPA in these seven experiments indicates maximum fruit drop reduction from the highest rate investigated. On an acid equivalent basis 3,5,6-TPA seems to be comparable to 2,4-D. Both NAA and 3,5,6-TPA were effective in controlling preharvest fruit drop in citrus under $\mathrm{CA}$ conditions. Both materials provided fruit holding late into the harvest season. NAA, and in particular 3,5,6-TPA, offer the potential to provide a substitute for 2,4-D which is commonly used for controlling fruit drop in many countries. Chemical names used: naphthaleneacetic acid (NAA); 3,5,6-trichloro-2-pyridinyloxyacetic acid (3,5,6TPA, triclopyr); 2,4-dichlorophenoxyacetic acid (2,4-D).
\end{abstract}

Abscission of mature fruit before harvest is a problem in many citrus producing countries. Increasing production and the desire for orderly fresh fruit marketing have made ontree storage of fruit an economic necessity. The synthetic auxin 2,4-D is often incorporated into citrus production practices to reduce preharvest drop of mature fruit.

2,4-D has a documented history of controlling mature citrus fruit drop in many citrus producing regions of the world (Coggins and Hield, 1968). A recent survey by Coggins found 2,4-D in commercial use in at least nine countries (El-Otmani et al., 2000). The screening for fruit drop controlling compounds in pome fruit production has been extensive (see Miller, 1988 for a review) but NAA remains in widespread use. Whereas citrus research on reducing mature fruit drop has not been as extensive as in pome fruit, perhaps due to the widespread efficacy of 2,4-D, several other compounds have been studied.

One of the first reports of auxin analog use in citrus was that of $100 \mathrm{mg} \cdot \mathrm{L}^{-1}$ naphthaleneacetamide applied to reduce mature fruit

Received for publication 24 Oct. 2000. Accepted for publication 18 June 2001. These experiments were supported in part by a grant from the California Citrus Research Board. Use of trade names does not imply endorsement of the products named nor criticism of similar ones not named. We thank statistician Carol Adams for her advice.

${ }^{1}$ Staff Research Associate.

${ }^{2}$ Professor. abscission of 'Pineapple' oranges in Florida (Gardner, 1941). Extensive studies done in California (CA) on citrus in the late 1940s with 2,4-D and related compounds identified 2,4,5-trichlorophenoxyacetic acid (2,4,5-T), 2-chlorophenoxyacetic acid, and naphthoxyacetic acid as having mature fruit abscission inhibiting properties on navel oranges (Stewart et al., 1951). 2,4,5-T was found to be about equal in effectiveness to 2,4-D for controlling preharvest drop of navel oranges. A compound similar to 2,4,5-T, 2,4,5-trichlorophenoxypropionic acid (2,4,5-TP, fenoprop) was reported to be effective for controlling mature fruit drop of 'Pineapple' oranges in Florida (Sites, 1954).

In another study, three auxin analogs and two inhibitors of ethylene biosynthesis were found to be effective in controlling abscission of lemon buttons (the calyx and a short piece of stem) in stored fruit subjected to an ethylene atmosphere (Einset et al., 1981). These auxins included 4-amino-3,5,6trichoropicolinic acid (picloram), 3,5,6trichlo-2-pyridinyloxyacetic acid (3,5,6-TPA, triclopyr) and 4-chlorophenoxyacetic acid. The ethylene inhibitors included aminoethoxyvinylglycine (AVG) and amino-oxyacetic acid. The synthetic auxin 3,5,6-TPA (triclopyr) has been shown to control preharvest drop of mature 'Navelate' oranges in Spain when applied at concentrations of 7.5 to $22.5 \mathrm{mg} \cdot \mathrm{L}^{-1}$ (Almela et al., 1997).

3,5,6-TPA seems to hold some promise as a plant growth regulator (PGR). In addition to the reports mentioned above, it has been shown to increase fruit size in 'Clausellina' mandarin (Agusti et al., 1994) and clementine 'Fina' mandarin (Agusti et al., 1995). It also has been reported to reduce mature drop of 'Winesap' apples (Marini et al., 1989) and hasten the maturation of peaches and nectarines (Agusti et al., 1996). All of these reports used $3,5,6$-TPA in the 7.5 to $25 \mathrm{mg} \cdot \mathrm{L}^{-1}$ range. Currently the only registered use for 3,5,6TPA for a food crop in the United States is as a selective herbicide in rice (Farm Chemicals Handbook, 1997). NAA has widespread use as a PGR. In the United States, it is currently registered for use for drop control and thinning in a variety of crops (Farm Chemicals Handbook, 1997).

A mature fruit drop control study on 'Tarocco' blood oranges in Italy indicated that ( \pm )-2-(4-chloro-2-methylphenoxy)propionic acid (CMPP, mecoprop) used at 40 $\mathrm{mg} \cdot \mathrm{L}^{-1}$ was not effective in controlling drop and, in fact, increased drop as compared to an untreated control (Dettori et al., 1992). This study also indicated that $40 \mathrm{mg} \cdot \mathrm{L}^{-1}$ of 2,4 dichlorophenoxypropionic acid (2,4-DP) was not as effective as $20 \mathrm{mg} \cdot \mathrm{L}^{-1}$ of $2,4-\mathrm{D}$ in controlling drop. This report underscores the importance of screening auxin analogs for mature fruit drop controlling properties. The ethylene inhibitor AVG, when applied preharvest to citrus, was found to be ineffective in controlling mature fruit drop in Florida (Davies et al., 1997) and California (Coggins and Anthony, unpublished data).

While 2,4-D remains effective in controlling mature fruit drop in citrus and has widespread efficacy, reliance on a single compound is perilous. Since both 3,5,6-TPA and NAA are readily available and currently registered on one or more food crops, we undertook the study presented in this paper to determine if either could substitute for 2,4-D in controlling preharvest mature fruit drop in citrus.

\section{Materials and Methods}

Over a period of nine years, 17 fruit drop control experiments were conducted in several CA locations on navel orange [Citrus sinensis (L.) Osbeck] and grapefruit (Citrus paradisi Macfadyen) trees. The materials investigated for fruit drop control properties were NAA and 3,5,6-TPA. A 2,4-D treatment was included in the experiments against which to compare results, as this is a standard fruit drop control practice in California.

NAA experiments. The NAA experiments began with the 1987-88 crop season and ended with the 1993-94 crop season. There is no experiment reported for the 1990-91 crop season as data were lost in the freeze that occurred in Dec. 1990. Of the seven NAA experiments conducted on navel orange, five sites were located in the San Joaquin Valley. The two remaining sites were located in a southern California (Riverside) location. The 1991-92 trial included the surfactants Latron AG-98 (Rohm and Haas, Philadelphia) and Silwet L-77 (Loveland Industries, Greeley, Colo.). Both surfactants were used at a rate of 
Table 1. Effect of naphthaleneacetic acid (NAA) on controlling mature navel orange fruit drop in the San Joaquin Valley. Mean drop of sound fruit, rounded to whole numbers, for the period drop was followed. Statistical analysis based on common log transformed values.

\begin{tabular}{|c|c|c|c|}
\hline \multirow{2}{*}{$\begin{array}{l}\text { Treatment } \\
\text { (acid equivalent) }\end{array}$} & \multicolumn{3}{|c|}{ Year } \\
\hline & $1987-88$ & $1988-89$ & 1989-90 \\
\hline Untreated control & 82 & 34 & 86 \\
\hline $16 \mathrm{mg} \cdot \mathrm{L}^{-1} 2,4-\mathrm{D}$ & 14 & 20 & 11 \\
\hline $25 \mathrm{mg} \cdot \mathrm{L}^{-1} \mathrm{NAA}$ & 52 & 30 & 59 \\
\hline $50 \mathrm{mg} \cdot \mathrm{L}^{-1} \mathrm{NAA}$ & 37 & --- & --- \\
\hline $100 \mathrm{mg} \cdot \mathrm{L}^{-1} \mathrm{NAA}$ & 31 & 24 & 35 \\
\hline $400 \mathrm{mg} \cdot \mathrm{L}^{-1} \mathrm{NAA}$ & $---^{z}$ & 28 & 19 \\
\hline Treatment effects $^{y}$ & 0.0001 & 0.0616 & 0.0001 \\
\hline \multicolumn{4}{|l|}{ Orthogonal contrasts } \\
\hline Control vs. treated & 0.0002 & 0.0604 & 0.0001 \\
\hline 2,4-D vs. NAA & 0.0001 & 0.0285 & 0.0001 \\
\hline NAA linear & 0.0257 & 0.5262 & 0.0001 \\
\hline NAA quadratic & 0.9746 & 0.2916 & 0.4105 \\
\hline Number of replications & 9 & 9 & 10 \\
\hline Elapsed days ${ }^{\mathrm{x}}$ & $152 / 150$ & $174 / 67$ & $174 / 83$ \\
\hline \multicolumn{4}{|l|}{ Site characteristics } \\
\hline Scion & Frost Nucellar Washington & Frost Nucellar Washington & Washington \\
\hline Rootstock & Troyer & Troyer & Rough lemon \\
\hline Year planted & 1965 & 1965 & 1954 \\
\hline
\end{tabular}

${ }^{\mathrm{z}}$ Not included at this site.

${ }^{y}$ Calculated $P$ value.

${ }^{x}$ First number is days from treatment to harvest. Second number is days from first count to harvest.
$0.025 \%(\mathrm{v} / \mathrm{v})$ of active ingredient. This was the only trial to include surfactants. For all experiments, the source of NAA was a commercial ammonium salt formulation (Fruit Fix Super Concentrate 800; Amvac Chemical Corp., Los Angeles). A range of NAA concentrations was used from 25 to 400 $\mathrm{mg} \cdot \mathrm{L}^{-1}$ (acid equivalent).

3,5,6-TPA experiments. The 3,5,6-TPA experiments began with the 1994-95 crop year and ended with the 1996-97 crop year. ducted at navel orange sites and five experiments were conducted at grapefruit sites. Three of the navel sites were in the San Joaquin Valley and two were located in southern California (Riverside). Three of the grapefruit sites were located in the Coachella Valley and two were in the Riverside area. Six of the ten 3,5,6-TPA experiments investigated only an acid formulation (Maxim; DowElanco, Iberica, S.A., Madrid, Spain), which is used commercially in some countries to increase fruit size in citrus. Four experiments compared this acid formulation to a triethylamine salt herbicide formulation (Garlon 3A; DowElanco, Indianapolis). The concentrations of 3,5,6-TPA investigated included 10,15 , and $20 \mathrm{mg} \cdot \mathrm{L}^{-1}$ (acid equivalent).

All of the NAA and 3,5,6-TPA experiments used a randomized complete-block design with single tree plots and 7 to 10 replications. All sites used were being managed for commercial production. Rootstocks varied from site to site, as did the navel cultivar. The Coachella Valley grapefruit sites were 'Redblush', whereas the Riverside grapefruit sites were 'Marsh' white. Details of scion/rootstock combinations and tree age are summarized in Tables 1-6. Trees were selected visually for uniformity of size and productivity before being included in an experiment. Trees were never used more than During this time, five experiments were con-
Table 2. Effect of naphthaleneacetic acid (NAA) in combination with two surfactants $(0.025 \%$ active ingredient) on controlling mature navel orange fruit drop in the San Joaquin Valley. Mean drop of sound fruit, rounded to whole numbers, for the period drop was followed. Statistical analysis based on common log transformed values. Seven single tree replications. Scion: Washington. Rootstock: Trifoliate. Year planted: 1967.

\begin{tabular}{lc}
\hline \hline $\begin{array}{l}\text { Treatment } \\
\text { (acid equivalent) + surfactant }\end{array}$ & \begin{tabular}{c} 
Year \\
\hline Untreated control
\end{tabular} \\
$16 \mathrm{mg} \cdot \mathrm{L}^{-1}$ 2,4-D + AG-98 & 55 \\
$16 \mathrm{mg} \cdot \mathrm{L}^{-1}$ 2,4-D + L-77 & 16 \\
$400 \mathrm{mg} \cdot \mathrm{L}^{-1} \mathrm{NAA}+$ AG-98 & 14 \\
$400 \mathrm{mg} \cdot \mathrm{L}^{-1} \mathrm{NAA}+\mathrm{L}-77$ & 14 \\
Treatment effects & 10 \\
Orthogonal contrasts & 0.0001 \\
$\quad$ Control vs. treated & \\
2,4-D vs. NAA & 0.0001 \\
AG-98 vs. L-77 & 0.1139 \\
2,4-D vs. NAA $\times$ AG-98 vs. L-77 & 0.1518 \\
Elapsed days & 0.6548 \\
& $172 / 116$
\end{tabular}

${ }^{2}$ Calculated $P$ value.

'First number is days from treatment to harvest. Second number is days from first count to harvest.

one season due to the possibility of introducing variable cropping from fruit holding or lack thereof the previous season. Treatments were applied to whole trees to the point of run off via high-pressure handgun sprayer at $\approx 28$ $\mathrm{kg} \cdot \mathrm{cm}^{-2}$ (400 psi). Treatments were made at the commercially recommended time of the year for controlling fruit drop (fall for navel orange, early winter for winter grapefruit and spring for summer grapefruit). 2,4-D was included in the experiments at concentrations ranging from 4 to $16 \mathrm{mg} \cdot \mathrm{L}^{-1}$ (acid equivalent). The 2,4-D was derived from the commercially available isopropyl ester product
(Citrus Fix; Amvac Chemical Corp., Los Angeles). No $\mathrm{pH}$ adjustments were made to any of the spray solutions.

Before fruit drop was anticipated to begin, all fruit on the ground under the trees were removed. Fruit drop counts were made regularly throughout the harvest season and dropped fruit were removed. Frequency of counts varied with intensity of drop from about every 2 weeks to two times a week. At the time of counting, dropped fruit were classified as sound, unsound and windfalls. Sound fruit had no visible signs of injury or infection. Unsound fruit had visible injury or pathological
Table 3. Comparisons of naphthaleneacetic acid (NAA) to 2,4-dichlorophenoxyacetic acid (2,4-D) on controlling mature navel orange fruit drop in San Joaquin Valley (1992-93 Site A) and Riverside County (1992-93 Site B and 1993-94 Site A) locations. Mean drop of sound fruit, rounded to whole numbers, for the period drop was followed. Statistical analysis based on common log transformed values. Seven single-tree replications.

\begin{tabular}{|c|c|c|c|}
\hline \multirow{2}{*}{$\begin{array}{l}\text { Treatment } \\
\text { (acid equivalent) }\end{array}$} & \multicolumn{2}{|c|}{ 1992-93 } & \multirow{2}{*}{$\begin{array}{c}1993-94 \\
\text { Site A } \\
\end{array}$} \\
\hline & Site A & Site B & \\
\hline Untreated control & 69 & 18 & 143 \\
\hline $4 \mathrm{mg} \cdot \mathrm{L}^{-1} 2,4-\mathrm{D}$ & 24 & 16 & 93 \\
\hline $8 \mathrm{mg} \cdot \mathrm{L}^{-1} 2,4-\mathrm{D}$ & 14 & 11 & 50 \\
\hline $16 \mathrm{mg} \cdot \mathrm{L}^{-1} 2,4-\mathrm{D}$ & 10 & $---^{\mathrm{z}}$ & --- \\
\hline $100 \mathrm{mg} \cdot \mathrm{L}^{-1} \mathrm{NAA}$ & 21 & --- & --- \\
\hline $200 \mathrm{mg} \cdot \mathrm{L}^{-1} \mathrm{NAA}$ & 11 & 10 & 55 \\
\hline $400 \mathrm{mg} \cdot \mathrm{L}^{-1} \mathrm{NAA}$ & 8 & 15 & 32 \\
\hline Treatment effects ${ }^{y}$ & 0.0001 & 0.0794 & 0.0001 \\
\hline \multicolumn{4}{|l|}{ Orthogonal contrasts } \\
\hline Control vs. treated & 0.0001 & 0.1673 & 0.0001 \\
\hline 2,4-D vs. NAA & 0.4153 & 0.3391 & 0.0060 \\
\hline 2,4-D linear & 0.0312 & 0.1298 & 0.0060 \\
\hline 2,4-D quadratic & 0.6013 & --- & --- \\
\hline NAA linear & 0.0070 & 0.0907 & 0.0109 \\
\hline 2,4-D quadratic & 0.1435 & --- & --- \\
\hline Elapsed days $^{x}$ & $187 / 125$ & $193 / 110$ & $156 / 63$ \\
\hline \multicolumn{4}{|l|}{ Site characteristics } \\
\hline Scion & Washington & Washington & Washington \\
\hline Rootstock & Unknown & Troyer & Troyer \\
\hline Year planted & ca 1910 & 1984 & 1984 \\
\hline
\end{tabular}

${ }^{\mathrm{z}}$ Not included at this site.

'Calculated $P$ value.

${ }^{x}$ First number is days from treatment to harvest. Second number is days from first count to harvest. 
Table 4. Effect of 3,5,6-trichlo-2-pyridinyloxyacetic acid (3,5,6-TPA) on controlling mature fruit drop. Site A is on grapefruit in Riverside County, Site B is on navel orange in the San Joaquin Valley and Site C is on grapefruit in the Coachella Valley. Mean drop of sound fruit, rounded to whole numbers, for the period drop was followed. Statistical analysis based on common log transformed values. Ten single-tree replications at each site.

\begin{tabular}{lccc}
\hline \hline Treatment & \multicolumn{3}{c}{$1994-95$} \\
(acid equivalent) & Site A & Site B & Site C \\
\cline { 2 - 4 } Untreated control & 91 & 22 & 78 \\
$16 \mathrm{mg} \cdot \mathrm{L}^{-1}$ 2,4-D & 13 & 13 & 24 \\
$10 \mathrm{mg} \cdot \mathrm{L}^{-1}$ 3,5,6-TPA & 15 & 12 & 24 \\
$15 \mathrm{mg} \cdot \mathrm{L}^{-1}$ 3,5,6-TPA & 12 & 7 & 24 \\
$20 \mathrm{mg} \cdot \mathrm{L}^{-1}$ 3,5,6-TPA & 9 & 8 & 21 \\
Treatment effects & 0.0001 & 0.0001 & 0.0001 \\
Orthogonal contrasts & & & \\
$\quad$ Control vs. treated & 0.0001 & 0.00001 & 0.0001 \\
2,4-D vs. 3,5,6-TPA & 0.3822 & 0.0617 & 0.6363 \\
3,5,6-TPA linear & 0.0046 & 0.0116 & 0.5727 \\
$\quad$ 3,5,6-TPA quadratic & 0.3960 & 0.5575 & 0.6247 \\
Elapsed days & $74 / 56$ & $201 / 121$ & $151 / 117$ \\
Site characteristics & & & \\
$\quad$ Scion & Marsh White & Atwood & Red Blush \\
Rootstock & Troyer & Troyer & Troyer \\
$\quad$ Year planted & 1970 & 1964 & 1974 \\
\hline
\end{tabular}

${ }^{2}$ Calculated $P$ value.

${ }^{\mathrm{y}}$ First number is days from treatment to harvest. Second number is days from first count to harvest.
Table 5. Effect of 3,5,6-trichlo-2-pyridinyloxyacetic acid (3,5,6-TPA) on controlling mature fruit drop. Site A is on navel orange in Riverside County, Site B is on navel orange in the San Joaquin Valley and Site C is on grapefruit in the Coachella Valley. Mean drop of sound fruit, rounded to whole numbers, for the period drop was followed. Statistical analysis based on common log transformed values. Ten single-tree replications at each site.

\begin{tabular}{lccc}
\hline \hline Treatment & \multicolumn{3}{c}{$1995-96$} \\
(acid equivalent) & Site A & Site B & Site C \\
\hline Untreated control & 159 & 247 & 32 \\
$16 \mathrm{mg} \cdot \mathrm{L}^{-1}$ 2,4-D & 29 & 35 & 19 \\
$10 \mathrm{mg} \cdot \mathrm{L}^{-1}$ 3,5,6-TPA & 17 & 64 & 24 \\
$15 \mathrm{mg} \cdot \mathrm{L}^{-1}$ 3,5,6-TPA & 14 & 49 & 22 \\
$20 \mathrm{mg} \cdot \mathrm{L}^{-1}$ 3,5,6-TPA & 14 & 40 & 18 \\
Treatment effects & 0.0001 & 0.0001 & 0.0003 \\
Orthogonal contrasts & & & \\
$\quad$ Control vs. treated & 0.0001 & 0.0001 & 0.0002 \\
2,4-D vs. 3,5,6-TPA & 0.0001 & 0.1367 & 0.2829 \\
3,5,6-TPA linear & 0.5228 & 0.0021 & 0.0182 \\
$\quad$ 3,5,6-TPA quadratic & 0.5640 & 0.5784 & 0.2573 \\
Elapsed days & $130 / 55$ & $178 / 115$ & $166 / 114$ \\
Site characteristics & & & \\
$\quad$ Scion & Washington & Washington & Red Blush \\
Rootstock & Troyer & Troyer & Troyer \\
Year planted & 1984 & 1975 & 1974 \\
\hline Calculated & & &
\end{tabular}

${ }^{2}$ Calculated $P$ value.

${ }^{y}$ First number is days from treatment to harvest. Second number is days from first count to harvest. infection which we assumed induced abscission. Windfalls showed signs of being torn from the trees and were not counted. Drop counts continued until the groves were harvested. All trees were harvested at the same time within an experiment. The number of dropped sound fruit was transformed to common logs to homogenize the variance. Analysis of variance, including orthogonal contrasts, was done on the transformed data. For experiments involving treatment at different rates, contrasts for linear and quadratic trends over rates used the $\log$ transformed values. No statistical comparisons were made between locations or years. All analyses were done with the SAS statistical package (Version 6.12, SAS Institute, Cary, N.C.).

\section{Results and Discussion}

NAA experiments. The NAA study began as a screening process to elucidate alternatives to 2,4-D for controlling preharvest fruit drop in citrus. The concentrations applied thus evolved over time as our knowledge of the material's fruit drop control potential increased. Of the seven experiments presented, five experiments had substantial mature fruit drop (defined here as $>50$ fruit per tree for the untreated control). In the five experiments that had substantial drop, NAA reduced drop by a statistically significant level in every case (Tables 1-3). NAA reduced drop by $31 \%$ to $88 \%$ as compared to the untreated control in these five experiments. This response is in agreement with Gardner (1941). Due to the large differences in concentrations needed to produce a similar effect, it is difficult to compare NAA directly to 2,4-D. Although we found concentrations as low as $25 \mathrm{mg} \cdot \mathrm{L}^{-1}$ of NAA to control drop, numerically the most effective range was 100 to $400 \mathrm{mg} \cdot \mathrm{L}^{-1}$ (acid equivalent). There was a statistically signifi- cant linear effect for NAA rate in every experiment that had multiple rates applied and that had substantial drop. The two sites with a small amount of drop are included to demonstrate the variation that can occur with fruit drop over years and locations. The mode of action of NAA in reducing mature fruit drop was not investigated in this study, but perhaps NAA is inhibiting cellulase activity as has been demonstrated for 2,4-D (Goren, 1993). When used in citrus at an early stage of fruit development for thinning, NAA has been shown to enhance ethylene production leading to increased cellulase activity and fruitlet drop (Iwahori and Oohata, 1976).

Since the severity of fruit drop cannot be predicted, the standard commercial practice is to apply a drop reducing spray as insurance before drop becomes a problem. Additionally, sprays made later in the season can have negative consequences on the spring cycle of growth (navels and winter grapefruit). Many varieties of citrus have a prolonged period of time when the fruit are mature and stored on the tree. Thus, a high NAA dose may be required to maximize effectiveness during this long holding period. We found that treatments of 100 to $400 \mathrm{mg} \cdot \mathrm{L}^{-1}$ (acid equivalent) of NAA controlled drop for as long as $187 \mathrm{~d}$ after application. No negative effects were seen from the NAA treatments. Although we found that relatively high concentrations of NAA are required to control drop to the same extent as 2,4-D, NAA may prove useful were citrus fruit drop control is needed in close proximity to 2,4-D sensitive crops.

3,5,6-TPA experiments. Ten experiments were conducted and seven of these had substantial fruit drop $(>50$ fruit per tree for the untreated control). In all seven experiments where there was substantial drop, 3,5,6-TPA reduced drop by a highly statistically significant level (Tables 4-6). In these seven experi- ments, 3,5,6-TPA reduced drop $69 \%$ to $96 \%$ as compared to the control. These results are consistent with a report from Spain of reduced fruit drop of mature oranges (Almela et al., 1997). In the four experiments that compared the acid form of 3,5,6-TPA with the triethylamine salt form, no differences in efficacy were found between the two forms (Table 6). These results agree with a report comparing the efficacy of various forms of 2,4-D for controlling mature fruit drop in citrus (Anthony and Coggins, 1999). The $20 \mathrm{mg} \cdot \mathrm{L}^{-1}$ rate of 3,5,6-TPA had significantly lower mature fruit drop (statistically significant linear component) as compared to the 10 and $15 \mathrm{mg} \cdot \mathrm{L}^{-1}$ rates in seven of the ten experiments. Comparing 3,5,6-TPA to 2,4-D at the seven trials with substantial drop, it is seen that 3,5,6-TPA (averaged over the concentrations) performed equal to 2,4-D in four experiments and better than 2,4-D in three experiments. The data for the three low fruit drop sites are included to demonstrate the variation that can be encountered in fruit drop studies. Two of the three low drop experiments still demonstrated fruit drop control with a treatment of $2,4-\mathrm{D}$ or $3,5,6$ TPA. No substantial negative effects were observed from the 3,5,6-TPA treatments.

Since 3,5,6-TPA is a synthetic auxin and demonstrates many of the same properties as 2,4-D, it can be speculated that the mode of action in reducing mature fruit drop in citrus is a reduction in cellulase activity in the abscission zone as mentioned above. On an acid equivalent basis, 3,5,6-TPA was comparable to that of 2,4-D for controlling preharvest fruit drop. If 2,4-D should become unavailable to the California citrus industry, 3,5,6-TPA would be a logical substitute to pursue.

In summary, both NAA and 3,5,6-TPA were effective in controlling preharvest fruit drop in citrus under California conditions. Both materials provided fruit holding late into 
Table 6. Comparisons of acid and amine forms of 3,5,6-trichlo-2-pyridinyloxyacetic acid (3,5,6-TPA) on controlling mature fruit drop. Site D and A were in Riverside County on grapefruit and navel orange, respectively. Site B is on navel orange in the San Joaquin Valley and Site C is on grapefruit in the Coachella Valley. Mean drop of sound fruit, rounded to whole numbers, for the period drop was followed. Statistical analysis based on common log transformed values. Ten single-tree replications at each site.

\begin{tabular}{|c|c|c|c|c|}
\hline \multirow{2}{*}{$\begin{array}{l}\text { Treatment } \\
\text { (acid equivalent) }\end{array}$} & \multirow{2}{*}{$\frac{1995-96}{\text { Site D }}$} & \multicolumn{3}{|c|}{ 1996-97 } \\
\hline & & Site A & Site B & Site C \\
\hline Untreated control & 79 & 171 & 14 & 106 \\
\hline $16 \mathrm{mg} \cdot \mathrm{L}^{-1} 2,4-\mathrm{D}$ & 19 & 31 & 7 & 31 \\
\hline $10 \mathrm{mg} \cdot \mathrm{L}^{-1} 3,5,6$-TPA acid & 19 & 16 & 13 & 29 \\
\hline $15 \mathrm{mg} \cdot \mathrm{L}^{-1} 3,5,6-\mathrm{TPA}$ acid & $---^{\mathrm{z}}$ & 6 & 14 & 22 \\
\hline $20 \mathrm{mg} \cdot \mathrm{L}^{-1} 3,5,6$-TPA acid & 16 & 6 & 13 & 23 \\
\hline $10 \mathrm{mg} \cdot \mathrm{L}^{-1} 3,5,6$-TPA amine & 21 & 23 & 13 & 29 \\
\hline $15 \mathrm{mg} \cdot \mathrm{L}^{-1} 3,5,6$-TPA amine & --- & 10 & 10 & 24 \\
\hline $20 \mathrm{mg} \cdot \mathrm{L}^{-1} 3,5,6$-TPA amine & 15 & 7 & 9 & 22 \\
\hline Treatment effects $^{\mathrm{y}}$ & 0.0001 & 0.0001 & 0.0538 & 0.0001 \\
\hline \multicolumn{5}{|l|}{ Orthogonal contrasts } \\
\hline Control vs. treated & 0.0001 & 0.0001 & 0.0652 & 0.0001 \\
\hline 2,4-D vs. 3,5,6-TPA & 0.4547 & 0.0001 & 0.0077 & 0.0152 \\
\hline 3,5,6-TPA acid vs. amine & 0.6874 & 0.2364 & 0.1179 & 0.8335 \\
\hline 3,5,6-TPA linear & 0.0111 & 0.0004 & 0.2445 & 0.0055 \\
\hline 3,5,6-TPA quadratic & --- & 0.4916 & 0.5891 & 0.3456 \\
\hline Acid vs. amine linear & 0.4290 & 0.6656 & 0.1319 & 0.8234 \\
\hline Acid vs. amine quadratic & --- & 0.2883 & 0.8854 & 0.6131 \\
\hline Elapsed days ${ }^{\mathrm{x}}$ & $82 / 81$ & $112 / 91$ & $183 / 126$ & $143 / 130$ \\
\hline \multicolumn{5}{|l|}{ Site characteristics } \\
\hline Scion & Marsh White & Washington & Washington & Red Blush \\
\hline Rootstock & Troyer & Troyer & Trifoliate & Troyer \\
\hline Year planted & 1970 & 1984 & 1975 & 1974 \\
\hline
\end{tabular}

y Calculated $P$ value.

${ }^{x}$ First number is days from treatment to harvest. Second number is days from first count to harvest.

the harvest season. NAA, and in particular 3,5,6-TPA, offer the potential to provide a substitute for 2,4-D which is commonly used for controlling fruit drop in many countries. The effectiveness of NAA and 3,5,6-TPA needs to be further verified under diverse climatic conditions.

\section{Literature Cited}

Agusti, M., V. Almela, M. Juan, E. Primo-Millo, I. Trenor, and S. Zaragoza. 1994. Effect of 3,5,6,trichloro-2-pyridyl-oxyacetic acid on fruit size
Agraria 10:15-22.

Anthony, M.F. and C.W. Coggins, Jr. 1999. The efficacy of five forms of 2,4-D to control preharvest fruit drop in citrus. Scientia Hort. 81:267277.

Coggins, C.W., Jr., and Hield, H.Z., 1968. Plant growth regulators, p. 371-389. In: W. Reuther, L.D. Batchelor, and H.J. Webber (eds.). The citrus industry, vol. II. Div. of Agr. Sci. Univ. of California, Berkeley.

Davies, F.S., C.A. Campbell, and G.R. Zalman. 1997. Gibberellic acid sprays for improving fruit peel quality and increasing juice yield of processing oranges. Proc. Fla. State Hort. Soc. 110:16-21.

Dettori, S., M. Pala, and D. Falqui. 1992. Evaluation of mecoprop (CMPP) to control preharvest drop in blood orange trees (Citrus sinensis L.). Proc. Intl. Soc. Citricult. 1:509-510.

Einset, J.W., J.L. Lyon, and P. Johnson. 1981 . Chemical control of abscission and degreening in stored lemons. J. Amer. Soc. Hort. Sci. 106:531-533.

El-Otmani, M., C.W. Coggins, Jr., M. Agusti , and C.J. Lovatt. 2000. Plant growth regulators in citriculture: World current uses. Crit. Rev. Plant Sci. 19(5):395-447.

Farm Chemicals Handbook. 1997. Volume 83. Meister Publishing Co., Willoughby, Ohio.

Gardner, F.E. 1941. Practical applications of plant growth substances in horticulture. Proc. Fla. State Hort. Soc. 54:20-26.

Goren, R. 1993. Anatomical, physiological and hormonal aspects of abscission in citrus. Hort. Rev. 15:145-182.

Iwahori, S. and J.T. Oohata. 1976. Chemical thinning of satsuma mandarin (Citrus unshiu Marc.) fruit by 1-naphthaleneacetic acid: Role of ethylene and cellulase. Scientia Hort. 4:167-174.

and yield of 'Clausellina' mandarin (Citrus unshiu Marc.). J. Hort. Sci. 69:219-223.

Agusti, M., M. El-Otmani, M. Aznar, M. Juan, and V. Almela. 1995. Effect of 3,5,6-trichloro-2pyridyloxyacetic acid on clementine early fruitlet development and on fruit size at maturity. J. Hort. Sci. 70:995-962.

Agusti, M., I. Andreu, M. Juan, F. Medina, and V. Almela. 1996. Empleo del 3,5,6-TPA para mejorar la calidad del fruto de melocotoneros y nectarinas. Fruticultura Profesional 81:49-61.

Almela, V., M. Juan, P. Lapica, J. Salvia, and M. Agusti. 1997. Control de la abscision del fruto maduro en los citricos. Comunitat Valenciana
Marini, R.P., R.E. Byers, and D.L. Sowers. 1989 Growth regulators and herbicides for delaying apple fruit abscission. HortScience 24:957-959.

Miller, S.S. 1988. Plant bioregulators in apple and pear culture. Hort. Rev. 10:309-401.

Sites, J.W. 1954. Controlling preharvest drop in Pineapple oranges with 2,4,5-trichlorophenoxypropionic acid. Proc. Fla. State Hort. Soc. 67:5659.

Stewart, W.S., L.J. Klotz, and H.Z. Hield. 1951. Effects of 2,4-D and related substances on fruitdrop, yield and quality of Washington navel oranges. Hilgardia 21:161-193. 